\title{
Pengalaman ibu bekerja dalam pemberian ASI eksklusif: Scoping review
}

\author{
Endah Kusumaningtyas Wahyudi ${ }^{1^{*}}$, Anjarwati ${ }^{2}$, Cesa Septiana Pratiwi ${ }^{3}$ \\ 1,2,3 Universitas 'Aisyiyah Yogyakarta, Yogyakarta, Indonesia
}

\section{INFORMASI ARTIKEL:}

\section{Riwayat Artikel:}

Tanggal diterima, 5 Oktober 2021

Tanggal direvisi, 4 Desember 2021

Tanggal dipublikasi, 30 Desember 2021

Kata kunci:

Pengalaman;

Ibu bekerja;

ASI eksklusif;

10.32536/jrki.v5i2.201

Keyword:

Experience;

Working mother;

Exclusive breastfeeding;

\section{ABSTRAK}

Latar belakang: ASI bermanfaat mencegah terjadinya perdarahan setelah persalinan, meningkatkan ikatan batin antara ibu dan bayi, sehingga dapat mengurangi kejadian AKI serta AKB. Salah satu penyebab hambatan pemberian ASI adalah pemberian MP ASI sebelum usia 6 bulan karena ibu bekerja. Dalam pemberian ASI, ibu memerlukan dukungan baik dari orangtua, dan suami. Tujuan penelitian: Untuk mereview mengenai pengalaman ibu bekerja dalam pemberian ASI Ekslusif di seluruh negara. Metode: Metode scoping review ini menggunakan framework Arksey \& O"Malley yang terdiri dari 5 tahap yaitu mengidentifikasi pertanyaan penelitian, mengidentifikasi sumber literature yang relevan, Pemilihan literature, memetakan data, menyusun, meringkas, dan melaporkan hasil pembahasan. Hasil: Berdasarkan hasil critical appraisal diperoleh 9 artikel dengan grade A. Hasil review diperoleh 4 tema yaitu dukungan dalam pemberian ASI Eksklusif, upaya ibu dalam pemberian ASI Eksklusif, faktor yang mempengaruhi keberhasilan pemberian ASI Eksklusif dan hambatan dalam pemberian ASI Eksklusif. Hasil yang di dapat bahwa ibu yang bekerja dalam memberikan ASI Eksklusif itu sangat membutuhkan adanya dukungan dari keluarga, tempat kerja, teman sebaya, dan fasilitas kesehatan untuk keberhasilan ibu dalam memberikan ASI Eksklusif. Simpulan: Pemberian ASI Eksklusif pada ibu bekerja sangat membutuhkan dukungan dari keluarga, tempat kerja, teman sebaya, dan fasilitas Kesehatan. Ibu yang menerima dukungan yang memadai meningkatkan kesuksesan dalam pemberian ASI Eksklusif.

Background: Breastmilk (ASI) is helpful to prevent bleeding after childbirth, increasing the bond between mother and infant, to reduce the incidence of $M M R$ and IMR. One cause of barriers to breastfeeding is the provision of MP ASI before the age of 6 months because the mother works. In breastfeeding, mothers need support from both parents and husbands. Objectives: To review the experience of working mothers in exclusive breastfeeding in all countries. Methods: This method was scoping review using the Arksey \& O"Malley framework which consisted of 5 stages, namely identifying research questions, identifying relevant literature sources, selecting literature, mapping data, compiling, summarizing, and reporting the results of the discussion. Results: Based on the results, the critical appraisal obtained 9 articles with grade $A$. The results of the review obtained 4 themes consisting of support in exclusive breastfeeding, mother's efforts in exclusive breastfeeding, factors that influence the success of exclusive breastfeeding, and barriers in exclusive breastfeeding. The results obtained those mothers who worked in exclusive breastfeeding need support from their families, workplaces, peers, and health facilities for success in providing exclusive breastfeeding. Conclusion: Working mothers providing exclusive breastfeeding need support from family, workplace, peers, and health facilities. Mothers who receive adequate support increase success in exclusive breastfeeding.

\section{Pendahuluan}

ASI Eksklusif yaitu pemberian Air Susu ibu sampai 6 bulan sejak awal masa kehidupan bayi

\footnotetext{
* Korespondensi penulis.

Alamat E-mail: tyasendah0707@gmail.com
}

tersebut tanpa pemberian asupan makanan tambahan ataupun minuman lain (Putu et al., 2020).

Berdasarkan World Health Organization (WHO) pada tahun 2016 menunjukkan bahwa $44 \%$ dari bayi baru lahir di dunia yang memperoleh ASI 
dalam usia 6 bulan masih sedikit, cakupan pemberian ASI eksklusif di Afrika Tengah sebanyak $25 \%$, Amerika Latin serta Karibia sebanyak 32\%, Asia Timur sebanyak $25 \%$, Asia Selatan 47\% dan negara berkembang sebanyak $46 \%$ oleh dari itu maka dapat disimpulkan bahwa secara keseluruhan kurang dari 40\% anak dibawah usia 6 bulan diberi ASI secara eksklusif (WHO, 2015).

Di Indonesia pada tahun 2016 menyatakan profil bayi baru lahir pernah memperoleh ASI mencapai dengan umur 6 bulan yaitu sebanyak 29,5\%. Hal ini menunjukan bahwa adanya pelaksanaan pemberian ASI secara ekslusif belum memenuhi target (Kementerian Kesehatan Republik Indonesia, 2016).

ASI sangat bermanfaat dalam hal mencegah terjadinya perdarahan setelah persalinan, mengurangi resiko terkena penyakit anemia, menekan resiko terjadinya kanker ovarium dan payudara, adanya ikatan batin dari seorang ibu dengan bayi,bayi yang sehat sehingga dapat mengurangi kejadian AKI serta AKB, mengembangkan kualitas anak selanjutnya (Astutik, 2014).

Penyebab yang menjadi penghambat pada saat memberikan Air Susu Ibu adalah bayi yang berusia sebelum 6 bulan sudah diberikan MPASI. Kurangnya pengetahuan ibu mengenai kebutuhan gizi pada bayi dan adanya pengaruh dari adat istiadat (Suminar, 2012). Pada wanita yang sedang memberikan ASI atau menyusui harus mempunyai pikiran positif, tidak boleh mengalami kecemasan, karena kondisi psikologi ibu sangat mempengaruhi dan dapat menghambat kerja hormone yang memproduksi ASI (Adam et al., 2016).

Dalam memberian ASI Eksklusif pada bayi, wanita memerlukan bantuan dari kerabat seperti orangtua, suami, dan keluarga. Dukungan keluarga memiliki peran yang sangat besar dalam pemberian ASI Eksklusif. Bentuk dukungan yang diterima ibu dari keluarga yaitu berupa dukungan instrumental, dukungan emosional, dukungan informasi serta penghargaan dari keluarganya tersebut (Susilaningsih, 2013).

Undang - undang nomor 13 tahun 2003 mengenai ketenagakerjaan pasal 83 menjelaskan bahwa wanita yang bekerja masih memberikan ASI pada anaknya, maka diberikan suatu kesempatan yang bertujuan agar dapat menyusui bayinya saat bekerja. Sedangkan pada peraturan pemerintah
Nomor 33 Tahun 2012 pasal 6 tentang pemberian ASI secara Eksklusif menjelaskan bahwa setiap ibu yang melahirkan harus memberikan ASI Eksklusif kepada bayi yang telah dilahirkan.

Tujuan dalam Scoping Review yaitu untuk mereview mengenai pengalaman ibu bekerja dalam pemberian ASI Ekslusif di seluruh negara.

\section{Metode penelitian}

Metode dalam penelitian ini adalah Scoping Review yaitu pandangan terstruktur yang bisa dipakai menafsirkan masalah berlandas kebenaran menggambarkan pikiran melandasi kawasan riset, asal mula, data serta bentuk informasi yang ada (Tricco et al., 2016). Scoping Review bertujuan untuk menjawab setiap pertanyaan dari topik suatu penelitian yang telah ditentukan dengan berbagai sumber dalam artikel penelitian yang sama setelah itu dikelompokkan serta dapat membuat kesimpulan. Langkah Langkah pelaksanaan scoping review yaitu 1) mengidentifikasi pertanyaan penelitian; 2) mengidentifikasi sumber literature yang relevan; 3 ) Seleksi/Pemilihan literature; 4( memetakan data; 5) menyusun, meringkas, dan melaporkan hasil (Arksey \& O'Malley, 2005).

\section{Langkah 1: mengidentifikasi pertanyaan scoping review}

Peneliti menggunakan kerangka kerja adalah Population, Ekposure, Outcome atau Theme (PEOS) untuk membentuk pertanyaan serta dapat digunakan dalam pencarian suatu literature. Pada tahapan ini untuk mengidentifikasi konsep serta kunci dalam pencarian yang efektif atau relevan.

Tabel 1. Framework PEOS

\begin{tabular}{cll}
\hline Populasi & Eksposure & Outcome \\
\hline Ibu yang bekerja & Asi Ekslusif & Pengalaman \\
\hline
\end{tabular}




\section{Langkah 2: mengidentifikasi sumber literature yang relevan}

Mengidentifikasi sumber literarture yang relevan dilakukan setelah identifikasi pertanyaan scoping review dan memenuhi kriteria inklusi dan eksklusi.

Tabel 2. Kriteria Inklusi dan Eksklusi

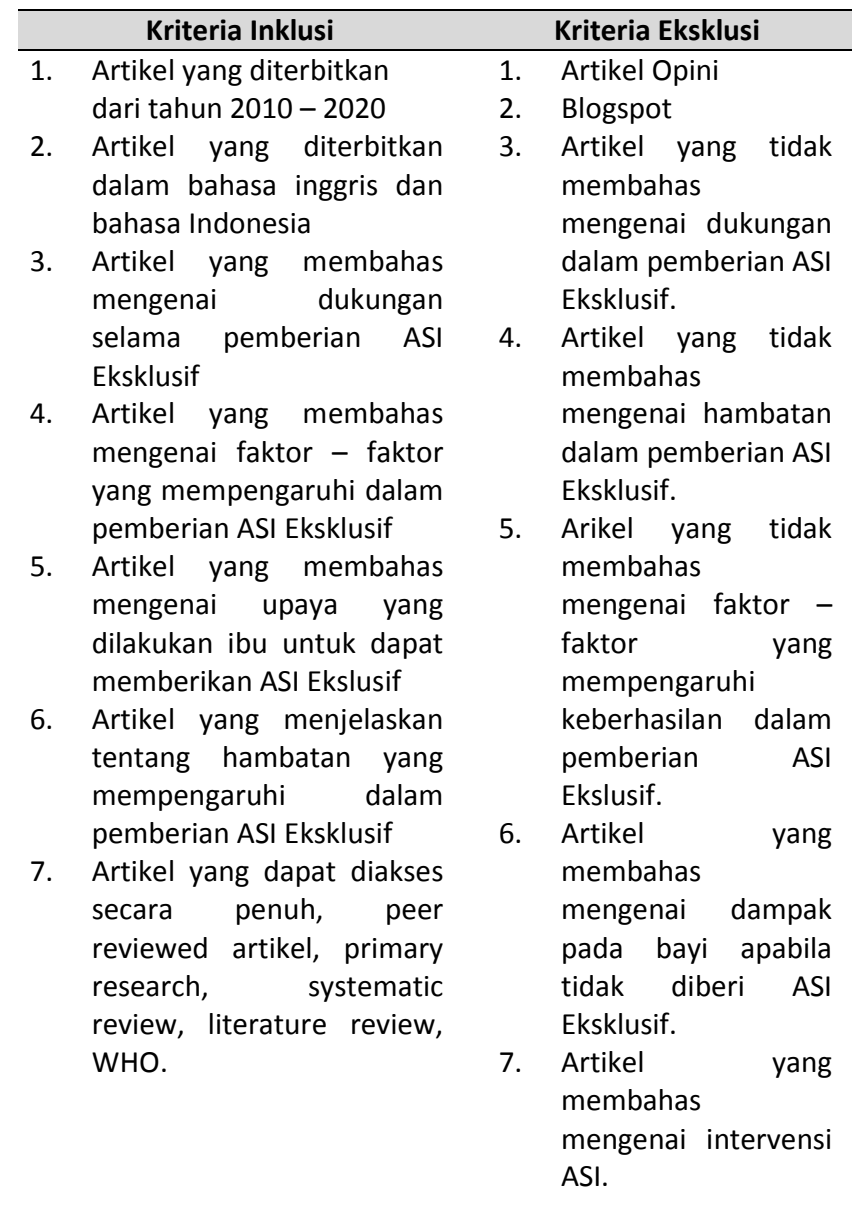

Dalam pencarian artikel menggunakan database yaitu pubmed, google scholar, sciendirect, dan willey. Kata kunci yang digunakan dalam pencarian literature dalam penelitian Scoping Review yaitu Mother works OR Working mother OR Working women OR Female works, Exclusive breastfeeding $O R$ Successful exclusive breastfeeding, Experience OR Perspektif OR Views.

\section{Langkah 3: Seleksi literature}

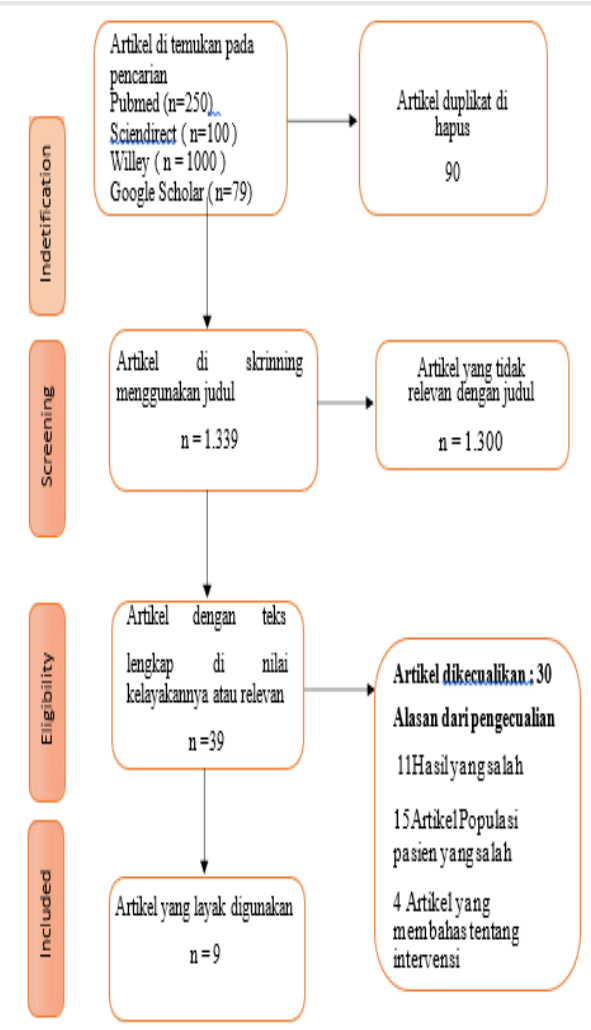

Gambar 1. Prisma Flow diagram Alur

Berdasarkan diagram Prisma Flow Chart didaptkan bahwa mendapat artikel yang telah di import ke mendeley untuk dilakukan skrining sebanyak 1.429. Setelah itu dilakukan seleksi pada artikel yang dapat digunakan yaitu 9 artikel yang diperoleh dengan menggunakan dengan penyaringan pada suatu artikel menggunakan program covidence untuk melakukan penilai pada artikel dengan melakukan Critical Appraisal, penilain pada artikel ini yaitu dengan lampiran Hawker (Hawker et al., 2002). 


\section{Langkah 4: Data Charting}

\section{Tabel 4. Data Charting}

\begin{tabular}{|c|c|c|}
\hline Tittle/ author /yaer & Country & Aim \\
\hline $\begin{array}{l}\begin{array}{l}\text { Examining working } \\
\text { experience of }\end{array} \text { of } \\
\text { exclusive }\end{array}$ & Ghana & $\begin{array}{l}\text { Tujuan dalam } \\
\text { penelitian ini yaitu } \\
\text { untuk mengetahui } \\
\text { pengalaman }\end{array}$ \\
\hline & & $\begin{array}{l}\text { pemberian ASI } \\
\text { eksklusif pada ibu } \\
\text { bekerja di Accra, ibu } \\
\text { kota Ghana }\end{array}$ \\
\hline
\end{tabular}

Result
Hasil penelitian menunjukkan bahwa
ada dua faktor utama yang
mempengaruhi pemberian ASI
Eksklusif pada ibu bekerja: praktik ASI
Eksklusif (pengetahuan dan
pemahaman tentang ASI Eksklusif,
dan pengalaman dalam ASI Eksklusif)
dan faktor tempat kerja (lama cuti
melahirkan, jam tutup, tidak adanya
kebijakan bersalin di organisasi,
dukungan kelembagaan yang tidak
memadai dan keseimbangan
kehidupan kerja serta keluarga.

\begin{tabular}{llll}
\hline Pengalaman ibu bekerja dalam & Indonesia & Tujuan penelitian ini Studi Kualitatif \\
memberikan ASI Eksklusif/ & untuk mengetahui dengan rancangan \\
Rusmala Dew dkki/2018 & pengalaman ibu studi deskriptif \\
& bekerja dalam fenomenologi \\
& memberikan ASI \\
& eksklusif
\end{tabular}

Pengalaman ibu bekerja dalam Indonesia Tujuan penelitian ini Studi Kualitatif Hasil dala, penelitian ini yaitu menghasilkan empat kategori yang menggambarkan pengalaman ibu bekerja dalam memberika ASI eksklusif. Kategori tersebut yaitu pengetahuan ibu tentang asi eksklusif, ASI perah, motivasi ibu dalam pemberian ASI eksklusif, upaya yang dilakukan ibu dalam memberikan asi eksklusif, dukungan keluarga dan dukungan tempat kerja.

Taking the path of least Australia Penelitian ini Studi Kualitatif Hasil dari penelitian ini Analisis

resistance: a qualitative analysis of return to work or study while breastfeeding/ Elaine Burns and Zoi Triandafilidis/2019

bertujuan untuk
mengeksplorasi
perempuan '
Pengalaman ibu
kembali bekerja atau
belajar sambil
mempertahankan
menyusui.
tersebut mengungkapkan empat tema. Tema pertama, Universitas sebagai lingkungan yang positif dan progresif untuk menyusui, mengeksplorasi staf dan siswa pengalaman cuti melahirkan, pengaturan kerja yang fleksibel, dan pengasuhan anak di kampus, dan hubungan mereka dengan tutor, supervisor, manajer, dan kolega. Tema kedua, Menemukan ruang pribadi dan aman untuk menyusui, menghadirkan staf dan siswa pengalaman menggunakan ruangan khusus, tempat parkir mobil, koridor, ruang kelas, dan kantor untuk menyusui dan memeras ASI, dan pengalaman mereka terkait dengan penyimpanan ASI. Tema ketiga, Merasa sadar diri dan tidak profesional, mencerminkan wanita ' Pengalaman mencampurkan kehidupan profesional dan pribadi mereka, dan merasa bersalah karena meluangkan waktu untuk menyusui. Tema keempat, Mengembangkan ketahanan terhadap penilaian, menangkap wanita ' Kesadaran bahwa pemberian ASI di kampus memerlukan pengembangan a " kulit tebal " dan kapasitas untuk tidak mudah tersinggung

\begin{tabular}{|c|c|c|c|c|c|}
\hline $\begin{array}{l}\text { A qualitative study investigating } \\
\text { the barriers to returning to work } \\
\text { for breastfeeding mothers in } \\
\text { Ireland/ Deirdre Desmond et.al/ } \\
2016\end{array}$ & Irlandia & $\begin{array}{l}\text { Tujuan dari penelitian } \\
\text { ini adalah untuk } \\
\text { mengetahui } \\
\text { hambatan ibu } \\
\text { kembali bekerja } \\
\text { untuk menyusui dan } \\
\text { untuk melihat } \\
\text { pengalaman ibu yang } \\
\text { tetap memberikan }\end{array}$ & Kualitatif & $\begin{array}{l}\text { Hasil dari penelitian ini yaitu para } \\
\text { wanita mencatat bahwa sikap budaya } \\
\text { di Irlandia ditambah dengan saran } \\
\text { yang tidak memadai atau tidak } \\
\text { konsisten dari para profesional } \\
\text { kesehatan menjadi tantangan } \\
\text { terbesar yang harus mereka atasi } \\
\text { untuk mencapai pemberian ASI } \\
\text { eksklusif selama } 6 \text { bulan. Temuan }\end{array}$ & $A$ \\
\hline
\end{tabular}


ASI untuk bayinya setelah kembali ke angkatan kerja.

penelitian ini menggambarkan bahwa ibu dengan keinginan untuk terus menyusui setelah kembali bekerja melakukannya dengan beberapa kesulitan. Banyak yang tidak mengungkapkan kepada majikannya bahwa mereka sedang menyusui dan tidak menanyakan tentang difasilitasi untuk terus menyusui setelah mereka kembali ke tempat kerja. Kurangnya dukungan dari majikan mereka serta rasa malu tentang status menyusui membuat banyak wanita menyembunyikan bahwa mereka menyusui setelah kembali ke tempat kerja.

\begin{abstract}
Work and breast milk feeding: a qualitative exploration of the experience of lactating mothers working in ready made garments factories in urban Bangladesh / AM Rumayan Hasan et.al/2020
\end{abstract}

\begin{aligned} & Bangladesh \multicolumn{2}{l}{ Tujuan dari penelitian } \\ & untuk mengeksplorasi \\ & hambatan dan \\ & fasilitator menyusui sertarang persepsi \\ & tentang penggunaan \\ & ASI di antara ibu yang \\ & bekerja di sektor RMG \end{aligned}

Metode kualitatif Hasil dari penelitian ini yaitu Tema utama eksplorasi kualitatif adalah pengetahuan dan pengalaman menyusui; penghalang struktural (rumah dan tempat kerja); konsekuensi dari pemberian ASI yang tidak memadai; serta persepsi dan pengalaman menggunakan ASI. Terlepas dari pengetahuan tentang manfaat ASI dan pentingnya menyusui selama 6 bulan, kebanyakan ibu memperkenalkan susu formula paling cepat 2 bulan untuk mempersiapkan mereka kembali bekerja. Hambatan seperti beban kerja yang berlebihan, fasilitas penitipan bayi yang tidak memadai $\mathrm{d}$ i tempat kerja, dan kurangnya pengasuh yang memadai di rumah menghambat pemberian ASI eksklusif. Para ibu dan pengasuh hanya memiliki sedikit pengetahuan tentang penggunaan ASI dan khawatir tentang kontaminasi.

\begin{tabular}{|c|c|c|c|c|c|}
\hline $\begin{array}{l}\text { I was determined to breastfeed, } \\
\text { and I always found a solution": } \\
\text { successful experiences of } \\
\text { exclusive breastfeeding among } \\
\text { Chinese mothers in Ireland/ } \\
\text { Qianling Zhou et.al/2020 }\end{array}$ & $\begin{array}{l}\text { Tionghoa } \\
\text { Irlandia }\end{array}$ & $\begin{array}{l}\text { Tujuan dari penelitian } \\
\text { ini adalah } \\
\text { pengalaman } \\
\text { menyusui eksklusif } \\
\text { yang sukses di antara } \\
\text { ibu-ibu imigran Cina }\end{array}$ & $\begin{array}{c}\text { Desain penelitian } \\
\text { kualitatif }\end{array}$ & $\begin{array}{l}\text { Hasil dari penlitianm ini yaitu faktor } \\
\text { berkontribusi pada pengalaman } \\
\text { sukses pemberian ASI eksklusif di } \\
\text { antara kelompok ibu imigran China, } \\
\text { termasuk penentuan nasib sendiri } \\
\text { yang kuat; kondisi fisik yang sesuai; } \\
\text { kesadaran akan manfaat ASI eksklusif; } \\
\text { kurangnya kendala waktu; dan } \\
\text { keluarga, dukungan profesional dan } \\
\text { kebijakan. Hambatan yang dihadapi } \\
\text { ibu antara lain kesulitan } \\
\text { menyeimbangkan ASI dan pekerjaan, } \\
\text { masalah kesehatan bayi, kendala } \\
\text { bahasa, ketidakmampuan untuk } \\
\text { mengonsumsi makanan tradisional } \\
\text { China pasca melahirkan, dan } \\
\text { kurangnya fasilitas ASI umum. } \\
\text { Tindakan yang dilakukan untuk } \\
\text { mengatasi hambatan tersebut antara } \\
\text { lain mencari dukungan keluarga, } \\
\text { istirahat selama masa menyusui, dan } \\
\text { memompa ASI untuk disusui dari } \\
\text { botol saat berada di luar rumah. }\end{array}$ & $A$ \\
\hline $\begin{array}{l}\text { The Role of Early Maternal } \\
\text { Support in Balancing Full-Time } \\
\text { Work and Infant Exclusive } \\
\text { Breastfeeding/Lea Pounds } \\
\text { et.al/2016 }\end{array}$ & Australia & $\begin{array}{l}\text { Tujuan dari penelitian } \\
\text { ini adalah untuk } \\
\text { memahami } \\
\text { bagaimana dukungan } \\
\text { ibu selama periode } \\
\text { postpartum } \\
\text { memengaruhi }\end{array}$ & Studi Kualitatif & $\begin{array}{l}\text { Hasil dari penelitian ini yaitu } \\
\text { dukungan yang diberikan kepada ibu } \\
\text { dapar memperlncar ibu bekerja } \\
\text { dalam memberikan ASI Ekslusif } \\
\text { kepada bayinya. }\end{array}$ & A \\
\hline
\end{tabular}




\begin{tabular}{|c|c|c|c|c|c|}
\hline & & $\begin{array}{l}\text { kemampuan ibu } \\
\text { untuk kemudian } \\
\text { menyeimbangkan } \\
\text { pekerjaan dan } \\
\text { menyusui, khususnya } \\
\text { pekerjaan penuh } \\
\text { waktu dan menyusui } \\
\text { eksklusif }\end{array}$ & & & \\
\hline $\begin{array}{l}\text { The enablers and barriers } \\
\text { continue breast milk feeding in } \\
\text { women returning to work } \\
\text { /Sulaiman/ } 2016\end{array}$ & Malaysia & $\begin{array}{l}\text { Penelitian ini } \\
\text { bertujuan untuk } \\
\text { menggambarkan } \\
\text { faktor pemungkin } \\
\text { yang dialami wanita } \\
\text { yang bekerja dan } \\
\begin{array}{l}\text { melanjutkan } \\
\text { pemberian } \\
\text { setelah ASI } \\
\text { kembali mereka } \\
\text { setelah melahirkan di } \\
\text { perkotaan }\end{array}\end{array}$ & Studi Kualitatif & $\begin{array}{l}\text { Hasil dari penelitian ini di dapatkan } \\
\text { Berdasarkan pengalaman } \\
\text { perempuan, kami } \\
\text { mengkategorikannya ke dalam tiga } \\
\text { kelompok: Wanita 'Passionate' } \\
\text { dengan tekad yang kuat dan } \\
\text { memberikan ASI eksklusif selama } 6 \\
\text { bulan, wanita 'Ambivalent' yang } \\
\text { memulai menyusui, tetapi dapat } \\
\text { mempertahankan ASI eksklusif } \\
\text { setelah kembali bekerja }\end{array}$ & A \\
\hline $\begin{array}{l}\text { The experiences of breastfeeding } \\
\text { mothers returning to work as } \\
\text { hospital nurses in } \\
\text { Pakistan/Saadia Riaz et.al/2018 }\end{array}$ & Pakistan & \begin{tabular}{lr}
\multicolumn{3}{l}{ Tujuan dari penelitian } \\
ini adalah untuk \\
Untuk \\
menggambarkan \\
sikap dan \\
pengalaman & ibu \\
menyusui r yang \\
kembali bekerja \\
penuh waktu sebagai \\
perawat di rumah \\
sakit tersier di \\
Pakistan.
\end{tabular} & Studi kualitatif & $\begin{array}{l}\text { Hasil dari penitian adalah Tiga tema } \\
\text { utama diidentifikasi fi ed: } \\
\text { kepercayaan pada seorang anak ' hak } \\
\text { untuk menyusui, con fl bertentangan } \\
\text { dengan kekuatan kelembagaan dan } \\
\text { pentingnya dukungan keluarga dalam } \\
\text { mempertahankan menyusui. Para ibu } \\
\text { sebelumnya menggambarkan } \\
\text { menyusui sebagai pilihan pemberian } \\
\text { makan bayi yang disukai dan anak ' } \\
\text { benar. Ketika kembali bekerja, para } \\
\text { ibu menghadapi kebijakan dan } \\
\text { praktik rumah sakit yang kaku, seperti } \\
\text { periode cuti melahirkan yang pendek } \\
\text { dan tidak dapat dinegosiasikan, di fl } \\
\text { pola shift yang fleksibel, dan } \\
\text { kurangnya penyediaan pengasuhan } \\
\text { anak. Orangtua ' Strategi untuk } \\
\text { melanjutkan menyusui termasuk } \\
\text { beberapa ibu yang membawa bayi ke } \\
\text { bangsal rumah sakit selama mereka } \\
\text { bekerja, dan bayi ayah yang } \\
\text { membawa bayinya ke rumah sakit } \\
\text { untuk disusui. Kesimpulan: Studi ini } \\
\text { menyoroti hambatan menyusui yang } \\
\text { dialami oleh ibu yang bekerja sebagai } \\
\text { perawat rumah sakit di Pakistan. Bayi } \\
\text { dapat berisiko karena strategi yang } \\
\text { diadopsi orang tua untuk } \\
\text { mendamaikan pemberian ASI yang } \\
\text { berkelanjutan dengan pekerjaan ibu. }\end{array}$ & $A$ \\
\hline
\end{tabular}




\section{Langkah 5: Maping Data}

Terdapat 3 tema yang diperoleh dari hasil review yang disajikan pada Tabel 5.

Tabel 5. Maping Data

\begin{tabular}{clc}
\hline No & \multicolumn{1}{c}{ Tema } & Nomor Artikel \\
\hline 1 & $\begin{array}{l}\text { Dukungan dalam } \\
\text { pemberian ASI Ekslusif } \\
\text { Upaya ibu untuk dapat } \\
\text { memberikan ASI Eksklusif : }\end{array}$ & A2, A4, A6, A7, A9 \\
3 & $\begin{array}{l}\text { Faktor - faktor yang } \\
\text { mempengaruhi } \\
\text { keberhasilan ASI Eksklusif: }\end{array}$ & A1,A2 \\
4 & $\begin{array}{l}\text { Hambatan yang } \\
\text { mempengaruhi dalam } \\
\text { memberikan ASI Eksklusif }\end{array}$ & A1, A2,A3, A4, A5, A6, \\
& & A8 \\
\hline
\end{tabular}

\section{Hasil dan Pembahasan}

Berdasarkan karakteristik artikel yang diperoleh sebanyak 9 artikel yang layak untuk digunakan dalam scoping review ini menggunakan metode dengan artikel yang terdapat dari negara berkembang yaitu dari negara berkembang Indonesia sebanyak 1 artikel, sedangkan pada negara maju yaitu Ghana sebanyak 1 artikel, Inggris sebanyak 1 artikel, Irlandia sebanyak 2 artikel, Bangladesh sebanyak 1 artikel, Australia sebanyak 1 artikel, Malaysia sebanyak 1 artikel, Pakistan sebanyak 1 artikel. Berdasarkan hasil penilaian, semua artikel kategori Grade A.

\section{Artikel berdasarkan}

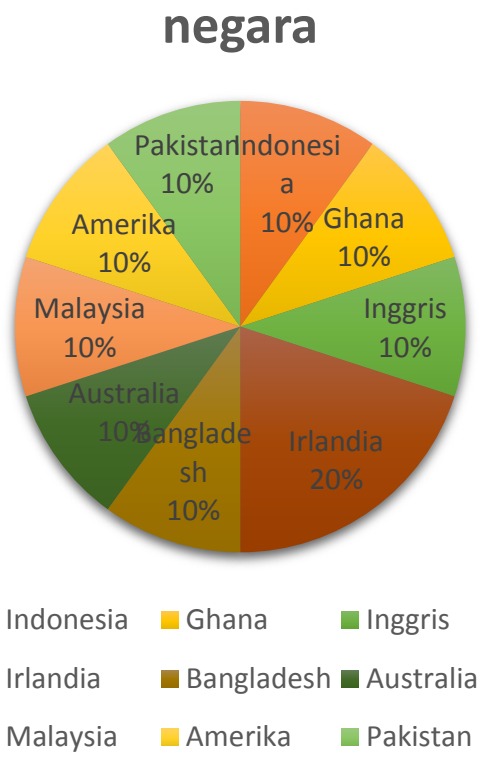

Gambar 1. Gambar Artikel berdasarkan Negara
Hasil review dari 9 artikel didapatkan 4 tema yaitu dukungan dalam pemberian ASI Ekslusif, upaya yang dilakukan ibu untuk dapat memberikan ASI Ekslusif, faktor - faktor yang mempengaruhi keberhasilan dalam pemberian ASI Ekslusif, hambatan yang mempengaruhi dalam memberikan ASI Eksklusif.

\section{Dukungan dalam pemberian ASI Eksklusif memfasilitasi}

\section{a. Dukungan keluarga}

Berdasarkan hasil penelitian Dewi, menyatakan bahwa dukungan oleh keluarga untuk mendukung dalam pemberian ASI Eksklusif kepada bayi, seperti suami, ibu kandung, ibu mertua, mendukung untuk memberikan asi eksklusif, dukungan yang diberikan oleh keluarga dalam keperluan yang dibutuhkan oleh ibu, pada penelitian ini dalam dukungan keluarga ini memberikan hasil bahwa adanya keberhasilan dalam dukungan keluaga pada pemberian ASI Eksklusif (Dewi \& Santy, 2018). Sejalan dengan penelitian yang mengatakan bahwa dukungan keluarga merupakan faktor eksternal yang paling besar pengaruhnya terhadap keberhasilan ASI Eksklusif. Ibu menyusui membutuhkan dukungan dan pertolongan, baik ketika memulai maupun melanjutkan menyusui hingga 2 tahun yaitu dukungan dari keluarga terutama suami dan tenaga kesehatan (Proverawati, 2010).

Menurut penelitian Zhou et al., 2020 bahwa dalam peneilitian ini didapatkan dukungan dari suami, orang tua, atau mertua. Dalam keluarga memberikan dukungan kepada ibu saat menyusui, ibu mengatakan bahwa dorongan dari anggota keluarga membantu mereka mengatasi kesulitan Selain itu, sebagian besar ibu menghargai dukungan fisik yang diberikan oleh anggota keluarga. Mereka juga percaya bahwa kemampuan mereka untuk beristirahat, melakukan aktivitas,dalam penelitian ini hasil yang ditemukan bahwa dukungan kelurga dapat memberikan kesuksesan dalam pemberian ASI Eksklusif (Zhou et al., 2020). Sejalan dengan adanyaa literature yang mengatakann bahwa dukungan atau support dari orang lain atau orang terdekat, sangatlah berperan dalam pemberian ASI Eksklusif. Semakin besar dukungan yang didapatkan untuk terus menyusui maka akan semakin besar pula 
kemampuan untuk dapat bertahan terus untuk menyusui (Proverawati, 2010).

Dalam penelitian Pounds et al., (2017) menjelaskan bahwa pada saat ingin kembali bekerja dukungan yang sangat berpengaruh terhadap pemberian asi eksklusif yaitu adanya dukungan keluarga memiliki peran yang sangat penting dalam hal memberikan asi eksklusif, pada saat ibu ingin kembali bekerja sangat berpengaruh dalam fisiologisnya dimana ibu tersebut belum sanggup untuk meninggalkan anaknya tersebut, yaitu mempengaruhi suasana hati dan tingkat energy, dalam hal ini penelitian menjelaskan dukungan dari keluaga sangat berpengaruh dalam suksesnya ASI Eksklusif (Pounds et al., 2017).

Dukungan dari suami atau keluarga sangat dibutuhkan oleh seorang ibu untuk lebih meningkatkan pemberian ASI Eksklusif pada bayinya (Wahyuningsih \& Machmudah, 2013). Berdasarkan penelitian Riaz \& Condon, (2019) menyatakan bahwa pemberian ASI Ekslusif pada saat ibu kembali bekerja, dukungan keluarga sangat diperlukan oleh sebab itu suami melakukan perjalanan ke tempat istrinya bekerja agar bayi tersebut tetap mendapat ASI Eksklusif. Keluarga mengatakan bahwa ASI itu sangat penting untuk pertumbuhan bayinya. Dukungan keluarga dalam mendorong ibu dalam pemberian ASI sangat berpengaruh terhadap keberhasilan pemberian ASI Eksklusif. Semakin besar dukungan yang dilakukan maka semakin besar pula kemampuan untuk bertahan terus dalam menyusui sampai bayi berusia 6 bulan.

\section{b. Dukungan tempat kerja}

Dukungan tempat kerja menurut Dewi adalah pada saat menyusui atau memberikan ASI eksklusif, lingkungan, teman kerja dan pimpinan tempat kerja memberikan dukungan. Bentuk dukungan yang diiberikan yaitu mendukung ibu dalam memompa ASI di ruangan khusus tempat bekerja yang tertutup, memperbolehkan dalam bekerja untuk memompa ASI. Hasil penelitian menemukan tempat kerja sangat mendukung dalam memberikan ASI Eksklusif ibu (Dewi \& Santy, 2018). Menurut Sulistyawati, salah satu bentuk dukungan adalah dengan menyediakan ruang dan peralatan memerah ASI di tempat kerja. Dukungan fasilitas peralatan dalam pemberian ASI Eksklusif di tempat kerja merupakan salah satu faktor penunjang yang penting dalam suksesnya penyelenggaraan pemberian ASI di tempat kerja (Sulistyowati, 2017).

\section{c. Dukungan teman sebaya}

Menurut Desmond \& Meany menjelaskan bahwa dukungan yang diberikan teman sebaya sangat lah penting dalam memberikan informasi praktis dan profesional, mendapatkan informasi melalui internet. Internet ini sumber yang baik serta menambah pengetahuan serta pengalaman bagaimana dalam pemberian ASI Ekslusif, hasil yang didapatkan bahwa dorongan dari teman sebaya sangat berpengaruh pada ibu dalam pemberian ASI Ekslusif (Desmond \& Meaney, 2016). Implementasi suatu program laktasi pada tempat kerja dengan memberikan adanya dukungan dari teman yang seusianya (Astuti \& Morgan, 2018).

\section{d. Dukungan Fasilitas Kesehatan}

Hasil dari penelitian ini Zhou et al., (2020) menjelaskan bahwa rumah sakit Irlandia menyediakan fasilitas menyusui, konsultasi, dan pendidikan. Fasilitas kesehatan terutama puskesmas memberikan pemeriksaan kesehatan dan dukungan laktasi secara teratur, bidan memberikan konseling laktasi (misalnya meredakan nyeri payudara). Penelitian ini menyebutkan hasil bahwa pemberian informasi sangat berpengaruh pada suksesnya pemberian ASI Eksklusif.

\section{Upaya ibu untuk dapat memberikan ASI eksklusif}

a. ASI perah

Menurut penelitian Abekah-Nkrumah et al., (2020) strategi ibu agar dapat melanjutkan ASI eksklusif pada bayinya saat kembali bekerja adalah dengan cara memerah ASI. Keluarga atau pengasuh yang menjaga bayi, memberikan ASI menggunakan botol selama ditinggal ibu bekerja. ASI perah dapat membantu dalam proses pemberian ASI Eksklusif. Sejalan dengan hasil penelitian Sulaiman, (2016) mengatakan bahwa upaya yang dilakukan ibu agar dapat memberikan ASI Ekslusif kepada anaknya dengan cara memerah ASI. ibu bisa memberikan ASI sampai 6 bulan dan dilanjutkan hingga 2 tahun. Pada penelitian Riaz \& Condon menjelaskan bahwa ibu yang sudah melakukan perah ASI, namun tidak ada fasilitas untuk menyimpan ASI perah tersebut seperti: tidak ada lemari es khusus, dan tidak ada sarana untuk membawa ASI yang diperah kepada bay, sehingga 
ASI tersebut tidak layak untuk diberikan lagi kepada bayi (Riaz \& Condon, 2019).

\section{b. Kebutuhan ibu saat memberikan ASI Eksklusif}

Berdasarkan hasil penelitian Dewi strategi ibu untuk dapat memberikan ASI eksklusif yaitu dengan meningkatkan pengetahuan ibu tentang ASI eksklusif. Upaya meningkatkan pengetahuan ibu dilakukan dnegan cara membaca buku, membaca artikel melalui internet, mengikuti grup di internet yang mendukung ASI eksklusif, meningkatkan asupan nutrisi, menghindari stress. Penelitian ini menemukan bahwa pemberian informasi, nutrisi berpengaruh dalam pemberian ASI (Dewi \& Santy, 2018).

Sejalan dengan adanya penelitian Zhou tahun 2020 mengatakan bahwa ASI yang diberikan kepada bayi, ibu menyusui dari bayi baru lahir, menyusui dengan interval yang lebih pendek dan lebih banyak dalam sehari, mempertahankan pola makan seimbang, istirahat dan berusaha mempertahankan suasana hati yang baik,untuk hal ini sangat berpengaruh terhadap ibu yang kembali bekerja menyusui bayinya (Zhou et al., 2020).

\section{Faktor - faktor yang mempengaruhi dalam keberhasilan pemberian ASI Eksklusif}

a. Pemahaman tingkat pengetahuan mengenai ASI Eksklusif

Berdasarkan hasil penelitian AbekahNkrumah, (2020) menyebutkan bahwa pengetahuan dan pemahaman mengenai ASI eksklusif menunjukan pengetahuan yang baik. Pemberian ASI eksklusif bertujuan untuk perkembangan fisik dan juga mental pada bayi mereka. Hasil ini berbanding lurus dengan penelitian Dewi yang menyatakan bahwa ASI ekslusif diberikan selama 6 bulan tanpa memberikan makanan tambahan yang lain pada bayi, dan dapat meningkatkan kecerdasan bayi (Dewi \& Santy, 2018). Hasil penelitian melengkapi pernyataan Maryunani, bahwa ASI adalah makanan terbaik untuk bayi, karena kandungan gizinya sangat khusus dan sempurna serta sesuai dengan kebutuhan tumbuh kembang bayi (Maryunani A., 2015).

\section{Hambatan yang mempengaruhi dalam pemberian asi eksklusif}

a. Hambatan tempat kerja

Menurut Abekah-Nkrumah et al., (2020) menunjukkan bahwa hambatan dalam pemberian
ASI eksklusif yaitu tidak adanya kebijakan dari tempat kerja dalam pemberian ASI eksklusif, pihak tempat kerja tidak menyediakan ruangan untuk memberikan ASI. Hambatan yang lain ditemukan dari hasil penelitian Desmond \& Meany (2016), yang menyatakan kurangnya persetujuan sosial untuk ibu menyusui dan pemberian ASI di tempat kerja tidak dianjurkan. Selain itu suatu organisasi atau tempat kerja ada yang mensyaratkan mereka harus berhenti menyusui atau menyembunyikan kegiatan dalam pemberian ASI eksklusif. Kurangnnya dukungan dari tempat kerja dalam fasilitas laktasi, penyimpanan susu perah juga menjadi masalah bagi sebagian perempuan yang tidak memiliki fasilitas untuk menyimpan susu di tempat kerja dan harus membawa ice pack dan cooler bag untuk bekerja dengan mereka guna menyimpan susu mereka. Mereka juga berbicara tentang kurangnya waktu yang tersedia bagi mereka untuk memeras susu selama hari kerja mereka. Tempat kerja yang tidak memperbolehkan ibu memberikan ASI Ekslusif pada anaknya akan sangat berpengaruh pada ibu serta akan menjadi stress yang menghambat keluarnya air susu ibu (Desmond \& Meaney, 2016).

Pada ibu bekerja pemberian ASI terhambat pada waktu untuk menyusui karena intensitas pertemuan antara ibu dan anak yang kadang berkurang. Ibu bekerja menjadikan alasan pekerjaan sebagai penghambat pemberian ASI (Hidayah Putri et al., 2018). Dalam penelitian Hasan et al., (2020) ini dijelaskan hambatan struktural yang menghalangi dalam pemberian ASI eksklusif adalah pada saat cuti kerja sudah selesai, pihak tempat kerja hanya mengizinkan untuk memberikan ASI kepada bayi selama tiga hari saja. Selebihnya pihak tempat kerja tidak mengizinkan lagi ibu dalam memberikan ASI. Akhirnya Banyak ibu memulai pemberian susu formula paling cepat 2 bulan setelah lahir untuk mempersiapkan mereka kembali bekerja setelah 3 bulan - 4 bulan cuti melahirkan. Para ibu terpaksa meninggalkan bayinya di rumah dengan pengasuh. Untuk waktu ibu bekerja yang sangat lama sehingga mulai memberikan susu formula sejak dini untuk membiasakan bayinya. Untuk memilih formula mana yang akan dibeli, mereka berkonsultasi dengan kerabat, tetangga, rekan kerja, dan dokter mereka.

Berdasarkan hasil penelitian Sulaiman et al, (2016) menyatakan saat ibu kembali bekerja, ibu tetap memberikan ASI Eksklusif dengan cara 
memerah ASI di kantor, tetapi tidak ada ruangan yang layak untuk memerah ASI dan tidak dilengkapi lemari es menyimpan ASI. Selain itu peneliti mendapatkan hasil bahwa pimpinan kurang mendukung dalam pemberian ASI, banyak pekerjaan yang harus diselesaikan oleh ibu dan hal ini menyebabkan ibu berfikir berhenti menyusui dan mengganti dengan susu formula. Tidak adanya dukungan tempat kerja berakibat pada keberhasilan pemberian ASI Eksklusif.

Ruang menyusui atau dikenal dengan ruang laktasi mempunyai arti penting bagi ibu pekerja karena fungsinya adalah memberikan kenyamanan bagi ibu, supaya dapat tetap memberikan ASI ekslusif kepada bayinya. Ketika menyusui bayi atau ketika memerah $\mathrm{ASI}$, ibu memerlukan ruangan yang bersih, nyaman dan tenang sehingga ibu tidak takut dan malu ketika harus mengeluarkan ASI saat berada di kantor (Mills, 2009).

Penelitian lain yang mendukung adalah tidak ada satupun dukungan baik dari teman kerja, pemimpin pada saat ibu mempunyai anak dan ingin menyusui, sehingga hambatan dari tempat kerja sangat berpebgearuh dalam pemberian ASI Ekskulsif (Burns \& Triandafilidis, 2019).

\section{b. Hambatan budaya}

Pada penelitian Zhou et al, (2020) menjelaskan bahwa hambatan budaya yaitu adanya masyarakat yang mengkritik bahwa menyusui di tempat umum itu negative setiap kali apabila ingin memberikan ASI Eksklusif pada saat berada diluar rumah. Penelitian ini menyebutkan bahwa pada saat ingin menyusui anaknya di depan umum ibu tersebut merasakan adanya komentar negatif dan merasa seperti ibu tersebut dilihat oleh masyarakat yang berada disana. Faktor sosial budaya yang lain yang memengaruhi ibu dalam pemberian ASI seperti meniru teman atau orang terkenal yang memberikan susu formula, faktor fisik ibu, faktor bayi, faktor tenaga kesehatan, meningkatnya promosi susu kaleng sebagai pengganti ASI, dan faktor psikologis ibu (Astutik., 2014).

c. Kesulitan yang dihadapi ibu dalam memberikan ASI Eksklusif

Menurut penelitian Dewi \& Santy, (2018) menjelaskan bahwa tingkat stress pada ibu menyusui dapat memengaruhi keberhasilan ibu dalam memberikan ASI Eksklusif. Produksi ASI sangat dipengaruhi oleh kejiwaan. Ibu yang selalu dalam keadaan gelisah, kurang percaya diri, rasa tertekan dan berbagai bentuk ketegangan emosional, akan dapat memengaruhi proses menyusui bayinya. Hasil penelitian menyebutkan ibu yang mengalami hal tersebut sangat berdampak pada psikologisnya sehingga menyebabakan ibu gagal dalam menyusui secara eksklusif.

Hasil penelitian lain menyebutkan faktor yang memengaruhi dalam pemberian ASI Eksklusif yaitu termasuk kuantitas dan kualitas ASI, masalah payudara, kekhawatiran tentang bentuk payudara, kesulitan menyusui setelah kembali bekerja, ketidakmampuan untuk menyeimbangkan laktasi dan aktivitas. Hasil dari penelitian ini menjelaskan bahwa apabila tidak adanya dukungan pada ibu akan mengakibatkan ibu menjadi stress sehingga ibu akan mengalami kesulitan dalam pemberian ASI Eksklusif (Zhou et al., 2020). Perlu kesiapan mental dan komitmen dalam pemberian ASI, sehingga dapat memotivasi ibu agar dapat menyusui, dan melakukan persiapan dalam pemenuhan kualitas gizi yang sangat bagus (Zhou et al., 2020).

\section{Simpulan}

Ibu yang bekerja dalam memberikan ASI Eksklusif sangat membutuhkan dukungan dari keluarga, tempat kerja, teman sebaya, dan fasilitas kesehatan. Upaya yang dilakukan ibu bekerja saat pemberian ASI Eksklusif yaitu dengan cara memerah ASI. Namun terdapat hambatan dalam pemberian ASI Eksklusif pada tempat kerja yaitu tidak tersedia fasilitas untuk laktasi, tidak tersedianya fasilitas yang layak untuk pemberian ASI serta adanya budaya masyarakat yang mengkritik bahwa menyusui di tempat umum itu adalah hal negative.

\section{Ucapan terima kasih}

Terima kasih kepada dosen Universitas 'Aisyiyah Yogyakarta yang telah membantu dalam penyusunan laporan ini sehingga dapat terselesaikan dengan sangat baik dan bisa dipublikasikan serta dapat berguna bagi pembaca. 


\section{Daftar Pustaka}

Abekah-Nkrumah, G., Antwi, M. Y., Nkrumah, J., \& Gbagbo, F. Y. (2020). Examining working mothers' experience of exclusive breastfeeding in Ghana. International Breastfeeding Journal, 15(1), 1-10. https://doi.org/10.1186/s13006-020-00300-0

Adam, S., Korompis, M., \& Alow, G. (2016). Perawatan Payudara Pada Masa Kehamilan Dan Pemberian Asi Eksklusif. Jurnal IImiah Bidan, 4(2), 227076.

Arksey, H., \& O’Malley, L. (2005). Scoping studies: Towards a methodological framework. International Journal of Social Research Methodology: Theory and Practice, 8(1), 1932.

https://doi.org/10.1080/1364557032000119 616

Astuti, A. W., \& Morgan, R. (2018). Interventions analysis of addressing exclusive breastfeeding (EBF) barriers to improve EBF coverage among industrial women employees in indonesia. Journal of Health Technology Assessment in Midwifery, 1(1), 1-16. https://doi.org/10.31101/jhtam.442

Astutik., R. . (2014). Payudara dan Laktasi. Salemba Medika.

Burns, E., \& Triandafilidis, Z. (2019). Taking the path of least resistance: A qualitative analysis of return to work or study while breastfeeding. International Breastfeeding Journal, 14(1), 1-13. https://doi.org/10.1186/s13006-019-0209-x

Desmond, D., \& Meaney, S. (2016). A qualitative study investigating the barriers to returning to work for breastfeeding mothers in Ireland. International Breastfeeding Journal, 11(1), 19. https://doi.org/10.1186/s13006-016-00758

Dewi, R., \& Santy, F. N. (2018). Pengalaman Ibu Bekerja Dalam Memberikan Asi Eksklusif. Jurnal Kesehatan Panca Bhakti Lampung, 6(2), 159. https://doi.org/10.47218/jkpbl.v6i2.51

Hasan, A. M. R., Smith, G., Selim, M. A., Akter, S., Khan, N. U. Z., Sharmin, T., \& Rasheed, S. (2020). Work and breast milk feeding: a qualitative exploration of the experience of lactating mothers working in ready made garments factories in urban Bangladesh. International Breastfeeding Journal, 15(1), 111. https://doi.org/10.1186/s13006-02000338-0

Hidayah Putri, D., Masrul, M., \& Evareny, L. (2018). The Relationship Between The Level of Maternal Knowledge, Maternal Employment Status and Family Support With Exclusive Breastfeeding in The Working Area of The Air Dingin Health Center of Padang City in 2018. Journal of Midwifery, 3(2), 161. https://doi.org/10.25077/jom.3.2.161175.2018

Kementerian Kesehatan Republik Indonesia. (2016). Profil Kesehatan Indonesia 2016. In Profil Kesehatan Provinsi Bali. http://www.depkes.go.id/resources/downloa d/pusdatin/profil-kesehatan-indonesia/ProfilKesehatan-Indonesia-2016.pdf

Maryunani A. (2015). Inisiasi Menyusu Dini, ASI Eksklusif dan Manajemen Laktasi. CV. Trans Info Media.

Mills, S. P. (2009). Workplace Lactation Programs. AAOHN Journal, 57(6), 227-231. https://doi.org/10.3928/0891016220090518-02

Pounds, L., Fisher, C. M., Barnes-Josiah, D., Coleman, J. D., \& Lefebvre, R. C. (2017). The Role of Early Maternal Support in Balancing Full-Time Work and Infant Exclusive Breastfeeding: A Qualitative Study. Breastfeeding Medicine, 12(1), 33-38. https://doi.org/10.1089/bfm.2016.0151

Proverawati, A. dan E. R. (2010). Kapita Selekta ASI dan Menyusui. Nuha Medika.

Putu, N., Sukma, W., S, W. C. W., Y, P. C. D., Studi, P., Dokter, P., Kedokteran, F., Udayana, U., \& Udayana, U. (2020). Perilaku Pemberian Asi Eksklusif Pada Wanita Pekerja Tenaga Kesehatan Rumah Sakit Umum Pusat Sanglah. Jurnal Medika Udayana, 9(1), 70-78.

Riaz, S., \& Condon, L. (2019). The experiences of breastfeeding mothers returning to work as hospital nurses in Pakistan: A qualitative study. Women and Birth, 32(2), e252-e258. https://doi.org/10.1016/j.wombi.2018.06.01 9 
Sulaiman, Z., Liamputtong, P., \& Amir, L. H. (2016). The enablers and barriers to continue breast milk feeding in women returning to work. Journal of Advanced Nursing, 72(4), 825-835. https://doi.org/10.1111/jan.12884

Sulistyowati, I. (2017). Pengaruh Dukungan Tempat Kerja terhadap ... (Indah sulistyowati , Oktaviani Cahyaningsih, Widya Mariyana) Pengaruh Dukungan Tempat Kerja terhadap ... ( Indah sulistyowati , Oktaviani Cahyaningsih, Widya Mariyana ). 58-63.

Suminar, dkk. (2012). Hubungan Pola Pemberian ASI dengan Peningkatan Berat Badan Bayi.

Susilaningsih, T. (2013). Gambaran Pemberian Asi Eksklusif Bayi 0-6 Bulan Di Wilayah Puskesmas Samigaluh li Tahun 2013. Jurnal Kesehatan Reproduksi, 4(2 Ags), 81-89. https://doi.org/10.22435/kespro.v4i2

Tricco, A. C., Lillie, E., Zarin, W., O’Brien, K., Colquhoun, H., Kastner, M., Levac, D., Ng, C., Sharpe, J. P., Wilson, K., Kenny, M., Warren, R., Wilson, C., Stelfox, H. T., \& Straus, S. E.
(2016). A scoping review on the conduct and reporting of scoping reviews. In BMC Medical Research Methodology. https://doi.org/10.1186/s12874-016-0116-4

Wahyuningsih, D., \& Machmudah. (2013). Dukungan suami dalam pemberian asi eksklusif. Jurnal Keperawatan Maternitas, 1(2), 93-101. http://download.portalgaruda.org/article.ph p ?article $=137438 \&$ val $=5088 \&$ title $=$ DUKUNGA N SUAMI DALAM PEMBERIAN ASI EKSKLUSIF

World Health Organization. (2015). world-healthstatistics-2015.

Zhou, Q., Chen, H., Younger, K. M., Cassidy, T. M., \& Kearney, J. M. (2020). "I was determined to breastfeed, and I always found a solution": successful experiences of exclusive breastfeeding among Chinese mothers in Ireland. International Breastfeeding Journal, 15(1), 47. https://doi.org/10.1186/s13006020-00292-x 